\title{
Developing indicators of pattern identification in patients with stroke using traditional Korean medicine
}

Ju Ah Lee ${ }^{1}$, Tae-Yong Park*, Jungsup Lee ${ }^{2}$, Tae-Woong Moon ${ }^{1}$, Jiae Choi ${ }^{1}$, Byoung-Kab Kang ${ }^{1}$, Mi Mi Ko ${ }^{1}$ and Myeong Soo Lee'

\begin{abstract}
Background: The traditional Korean medical diagnoses employ pattern identification (PI), a diagnostic system that entails the comprehensive analysis of symptoms and signs. The PI needs to be standardized due to its ambiguity. Therefore, this study was performed to establish standard indicators of the PI for stroke through the traditional Korean medical literature, expert consensus and a clinical field test.

Methods: We sorted out stroke patterns with an expert committee organized by the Korean Institute of Oriental Medicine. The expert committee composed a document for a standardized pattern of identification for stroke based on the traditional Korean medical literature, and we evaluated the clinical significance of the document through a field test.

Results: We established five stroke patterns from the traditional Korean medical literature and extracted 117 indicators required for diagnosis. The indicators were evaluated by a field test and verified by the expert committee.

Conclusions: This study sought to develop indicators of PI based on the traditional Korean medical literature. This process contributed to the standardization of traditional Korean medical diagnoses.
\end{abstract}

Keywords: Pattern identification, Indicator, Stroke, Standardization, TKM

\section{Background}

Pattern identification is a system of diagnosis in traditional Korean medicine (TKM) that is characterized by its own theoretical basis and practical experience [1]. This unique system entails a comprehensive symptom analysis and an investigation of the illness, its cause and nature, the patient's physical condition and the patient's treatment through four examinations (inspection, listening and smelling, inquiry and palpation) [2]. TKM has advantages, such as one-to-one personalized care accompanying the patient's diagnosis. However, these characteristics are criticized because of the ambiguous process of diagnosis. Different ways of pattern identifications are often used for diagnosis by different Oriental

\footnotetext{
* Correspondence: parkty77@kiom.re.kr

'Brain Disease Research Center, Korea Institute of Oriental Medicine, 1672

Yuseongdae-ro, Yuseong-gu, Daejeon 305-811, Republic of Korea

Full list of author information is available at the end of the article
}

medical clinicians in identical patients [3]. Oriental medical clinicians have claimed that differences exist between Western medicine and TKM in terms of therapy and the objective for treating and diagnosing patients. However, standardized and objective methods for diagnosis in TKM are needed. The Korea Institute of Oriental Medicine (KIOM) has conducted a fundamental study for the standardization and objectification of pattern identification in TKM for stroke (SOPI-Stroke) since 2005 [4-6]. We organized a committee comprised of physicians and researchers to draft a standardized document for pattern identification in stroke (D-SPI). This research concerned the process of developing standard indicators of pattern identification. This is a primary step of collecting and sorting clinical data toward further investigation on standardization of the pattern identification.

\section{C)

( 2011 Park et al; licensee BioMed Central Ltd. This is an open access article distributed under the terms of the Creative Commons Attribution License (http://creativecommons.org/licenses/by/2.0), which permits unrestricted use, distribution, and reproduction in any medium, provided the original work is properly cited. 
Table 1 Demographic parameters of study subjects

\begin{tabular}{lll}
\hline Characteristics & Male & Female \\
\hline number & 71 & 76 \\
\hline Age(years) & $62.01 \pm 11.96$ & $66.72 \pm 10.05$ \\
\hline
\end{tabular}

\section{Methods}

\section{Collecting of pattern indicators}

To determine important pattern indicators, the KIOM research team conducted manual searches of 10 academic sources: (1) the Dongeuibogam [7]; (2) A study of the standardization of diagnoses and diagnostic requirements in traditional Korean medicine II [8]; (3) Traditional Korean medicine diagnostics [9]; (4) Pattern identification diagnostics [10]; (5) Traditional Korean medicine pathology [11]; (6) A Standard form of pattern identification for stroke patients [12]; (7) A study of the standardization of diagnoses and diagnostic requirements in traditional Korean medicine III [13]; (8) The traditional Korean medical textbook on the digestive system [14]; (9) The traditional Korean medical textbook on the cardiovascular system [15]; and (10) Traditional Chinese medicine for encephalopathy [16]. Furthermore, we investigated clinical articles associated with stroke in the Korean literature, and then developed a set of necessary pattern indicators. Unnecessary pattern indicators included motor disability, dysphagia, dysarthria, and disturbances of consciousness. Although these indicators are primary symptoms of stroke, they were unhelpful in identifying a TKM pattern.

\section{Clinical application of pattern indicators}

We clinically applied these pattern indicators, verifying their usefulness and compatibility. Because the indicators were composed of old language, not all indicators fit the patients' symptoms. A total of 147 stroke patients, whose demographic parameters are presented in Table 1, were enrolled from these Oriental medicine hospitals: 2 Wonkwang University Oriental Medicine hospitals (WKU OHs) and Dae Jeon University Oriental Medicine Hospital (DJU OH). All patients provided informed consent under procedures approved by the respective Institutional Review Boards (IRB NO: I-0910/ 02-004).

Inclusion criteria were as follows: stroke patients within 30 days of symptom onset, confirmed by imaging, such as computerized tomography (CT) or magnetic resonance imaging (MRI). Exclusion criteria were as follows: traumatic stroke patients, such as subarachnoid, subdural and epidural hemorrhaging patients. Two TKM doctors independently completed the case report form (CRF). The clinical trial period ranged from May 1, 2005 to May 30, 2005. ${ }^{\mathrm{Q}}$

\section{Expert committee approval}

We organized a TKM expert committee (EC), which was launched on January 25, 2005, for our study: the fundamental study for the standardization and objectification of pattern identification in TKM for stroke (SOPI-Stroke). The EC was comprised of 19 members who majored in TKM from 11 Oriental medicine hospitals. More detailed description of the EC is presented in Table 2. At the first meeting of the EC that played a leading role in our study, the committee discussed the necessity of this project and the study design.

The case report form and standard operating procedures We compiled the CRF to include the D-SPI and basic patient information. The CRF was composed of shortform questions in Korean for all clinicians to identify patterns without prejudice or difficulty. We developed standard operating procedures (SOPs) based on the

Table 2 The Member of Expert Committee

\begin{tabular}{cllclc}
\hline Name & Affiliation & Major, Position & Name & Affiliation & Major, Position \\
\hline Byung Soon Moon & WKU & DCIM in TKM, professor & Ki Ho Cho & KHU & DCIM in TKM, professor \\
\hline Seong Gyu Ko & KHU & DCIM in TKM, professor & In Lee & PNUKM & DCIM in TKM, professor \\
\hline Jung Nam Kwon & DEU & DCIM in TKM, professor & Bum Sang Shim & KHU & DOPM in TKM, professor \\
\hline Yun Sik Kim & DJU & DCIM in TKM, professor & Sang Kwan Lee & WKU & DCIM in TKM, professor \\
\hline Sang Kwan Moon & KHU & DCIM in TKM, professor & Eun Chul Lim & DSOH & DSCM in TKM, head \\
\hline Se Jin Park & DSOH & DCIM in TKM, head & In Soo Jang & WSU & DCIM in TKM, professor \\
\hline Jong Hyung Park & KWU & DCIM in TKM, professor & Chan Yong Jun & KWU & DCIM in TKM, professor \\
\hline Chi Sang Park & DGU-2 & DCIM in TKM, professor & Chang Ho Han & DGU-1 & DCIM in TKM, professor \\
\hline In Chan Seol & DJU & DCIM in TKM, professor & Seok Hong & DSU & DCIM in TKM, professor \\
\hline Gil Cho Shin & DGU-1 & DCIM in TKM, professor & & &
\end{tabular}

KHU; Kyung Hee University, DEU; Dong Eui University, DJU; Dae Jeon University, DSOH; Dong Seo Oriental Hospital, KWU; Kyung Won University, DGU-1; Dong Guk University, DGU-2; Dae Gu University, PNUKM; Pusan National University, school of Korean Medicine, WKU; Wonkwang University, WSU; Woo Suk University, DSU; Dong Shin University

DCIM; Department of Circulatory Internal Medicine, DOPM; Department of Oriental Pathology Medicine, DSCM; Department of Sasang Constitutional Medicine, 
Table 3 Pattern indicators

\begin{tabular}{|c|c|c|c|c|}
\hline Number & Item & & Pattern Indicator & Freq. (\%) \\
\hline \multirow[t]{2}{*}{1} & body type & & underweight & $35(23.8)$ \\
\hline & & & overweight & $36(24.48)$ \\
\hline \multirow[t]{18}{*}{2} & headache & time & severe and sudden headache & $5(3.4)$ \\
\hline & & & old headache & $14(9.52)$ \\
\hline & & & continuous pain & $20(13.6)$ \\
\hline & & site & headache in the whole head & $22(14.96)$ \\
\hline & & & site-fixed headache & $8(5.44)$ \\
\hline & & & radiating headache & $3(2.04)$ \\
\hline & & aspect & severe and seems to be bursting & $4(2.72)$ \\
\hline & & & tightened feeling & $8(5.44)$ \\
\hline & & & headache with a pulling sensation & $5(3.4)$ \\
\hline & & & deterioration of headache by fatigue & $5(3.4)$ \\
\hline & & & hot head & $3(2.04)$ \\
\hline & & & headache with anger & $5(3.4)$ \\
\hline & & & heavy-headedness & $25(17)$ \\
\hline & & & an unpleasant sensation with an urge to vomit and pain in the head & $6(4.08)$ \\
\hline & & & un-refreshed head & $29(19.72)$ \\
\hline & & & headache accompanied by stabbing pain & $5(3.4)$ \\
\hline & & & headache accompanied by empty pain & $6(4.08)$ \\
\hline & & & headache accompanied by a hot flush & $3(2.04)$ \\
\hline \multirow[t]{2}{*}{3} & dizziness & & severe and accompanied nausea and vomiting & $6(4.08)$ \\
\hline & & & slight dizziness & $41(27.89)$ \\
\hline \multirow[t]{5}{*}{4} & facial complexion & & reddened complexion & $37(25.17)$ \\
\hline & & & dark face discoloration & $36(24.48)$ \\
\hline & & & black face with black eyelids & $21(14.28)$ \\
\hline & & & white complexion & $23(15.64)$ \\
\hline & & & pale face and red zygomatic site & 20 (13.6) \\
\hline \multirow[t]{4}{*}{5} & eye's abnormal & & red eyes & $31(21.08)$ \\
\hline & & & purpura in the sclera & $4(2.72)$ \\
\hline & & & dry eyes & $11(7.48)$ \\
\hline & & & excessive gum in the corner of the eye & $11(7.48)$ \\
\hline \multirow[t]{3}{*}{6} & tinnitus & & tinnitus is incidental & $1(0.68)$ \\
\hline & & & tinnitus is continuous & $4(2.72)$ \\
\hline & & & tinnitus is intermittent & $7(4.76)$ \\
\hline \multirow[t]{7}{*}{7} & tongue and mouth & & bitter taste in the mouth & $45(30.61)$ \\
\hline & & & thirst in the mouth & $48(32.65)$ \\
\hline & & & aphta and tongues sores & $4(2.72)$ \\
\hline & & & excessive saliva in the mouth & $17(11.56)$ \\
\hline & & & cyanotic lips & $17(11.56)$ \\
\hline & & & dry mouth & $77(52.38)$ \\
\hline & & & fetid mouth odor & $26(17.68)$ \\
\hline \multirow[t]{2}{*}{8} & sputum & & sticky sputum & $18(12.24)$ \\
\hline & & & phlegm rale & $32(21.76)$ \\
\hline \multirow[t]{2}{*}{9} & $\begin{array}{c}\text { oppression in the } \\
\text { chest }\end{array}$ & & heat vexation in the chest & $10(6.8)$ \\
\hline & & & feeling of oppression in the chest & $21(14.28)$ \\
\hline
\end{tabular}


Table 3 Pattern indicators (Continued)

\begin{tabular}{|c|c|c|c|}
\hline & & bloated feeling in the chest and hypochondriac region & $1(0.68)$ \\
\hline \multirow[t]{2}{*}{10} & palpitations and & palpitations and shortness of breath & (0) \\
\hline & & palpitation with anxiety or discomfort & $(0)$ \\
\hline \multirow[t]{6}{*}{11} & abdomen & tenderness and fever in abdominal diagnosis & $6(4.08)$ \\
\hline & & sounds heard in abdominal diagnosis & $17(11.56)$ \\
\hline & & tenderness of the lower abdomen and accompanied pain & $22(14.96)$ \\
\hline & & mass in the abdomen & $6(4.08)$ \\
\hline & & no resistance to touch of the abdomen & $44(29.93)$ \\
\hline & & tension is felt when pressing the abdomen & $40(27.21)$ \\
\hline \multirow[t]{6}{*}{12} & skin & burning skin sensation & $7(4.76)$ \\
\hline & & attachment sensation of derma & $18(12.24)$ \\
\hline & & purpura & $7(4.76)$ \\
\hline & & feeling like insects' crawling & $7(4.76)$ \\
\hline & & feeling chilly on the skin & $16(10.88)$ \\
\hline & & dry skin & $31(21.08)$ \\
\hline \multirow[t]{5}{*}{13} & palm and sole & vexing heat in the extremities & $14(9.52)$ \\
\hline & & a subjective heaviness sensation of the body & $76(51.7)$ \\
\hline & & a pronounced cold in the extremities up to the knees and elbows or beyond & $26(17.68)$ \\
\hline & & a lack of physical strength in the four extremities & $75(51.02)$ \\
\hline & & heat in the palms and soles & $20(13.6)$ \\
\hline \multirow[t]{5}{*}{14} & digestion & stomach feels full & 19 (12.92) \\
\hline & & feeling gastric reflux & $9(6.12)$ \\
\hline & & $\begin{array}{l}\text { excessive appetite with increased food intake and } \\
\text { recurrence of hunger sensation shortly after eating }\end{array}$ & $4(2.72)$ \\
\hline & & an unpleasant sensation with an urge to vomit & $17(11.56)$ \\
\hline & & loss of appetite & $41(27.89)$ \\
\hline \multirow[t]{2}{*}{15} & feces & hardened feces difficult to evacuate & $36(24.48)$ \\
\hline & & discharge of soft, unformed stools: a loose stool & $7(4.76)$ \\
\hline \multirow[t]{3}{*}{16} & urine & dark yellow or reddish urine & 49 (33.33) \\
\hline & & a high volume of transparent urine & $(0)$ \\
\hline & & failure of voluntary control of urination & 49 (33.33) \\
\hline \multirow[t]{4}{*}{17} & sleeping & inability to sleep well due to fever and oppression & $10(6.8)$ \\
\hline & & excessive sleepiness night and day & $4(2.72)$ \\
\hline & & inability to sleep or abnormal wakefulness: insomnia & $7(4.76)$ \\
\hline & & inability to sleep due to anxiety & $9(6.12)$ \\
\hline \multirow[t]{2}{*}{18} & heat condition & high fever & $34(23.12)$ \\
\hline & & tidal fever & $4(2.72)$ \\
\hline \multirow[t]{3}{*}{19} & sweat & profuse sweating with fever: sweating when having fever & $38(25.85)$ \\
\hline & & $\begin{array}{l}\text { lack of physical strength, excessive sweating during the daytime with no apparent cause, } \\
\text { such as physical exertion, hot weather, thick clothing or medication }\end{array}$ & $24(16.32)$ \\
\hline & & night sweating & $21(14.28)$ \\
\hline \multirow[t]{2}{*}{20} & vocal sound energy & inclined to speak or speaking at a high volume & $58(39.45)$ \\
\hline & & disinclined to speak or speaking at a low volume & $37(25.17)$ \\
\hline \multirow[t]{3}{*}{21} & tongue & $\begin{array}{c}\text { a larger than normal tongue, pale in color and } \\
\text { delicate, usually bearing dental indentations on the } \\
\text { margin-enlarged tongue }\end{array}$ & $9(6.12)$ \\
\hline & & a tongue with dental indentations on its margin: a teeth-marked tongue & $40(27.21)$ \\
\hline & & a tongue thinner than normal & $11(7.48)$ \\
\hline
\end{tabular}




\begin{tabular}{|c|c|c|c|}
\hline & & $\begin{array}{c}\text { a tongue redder than normal, indicating the presence of } \\
\text { heat }\end{array}$ & $56(38.09)$ \\
\hline & & a tongue with thorn-like protrusions on the surface & $10(6.8)$ \\
\hline & & a cyanotic tongue, indicating blood stasis or heat toxin in the nutrient-blood & $17(11.56)$ \\
\hline & & a tongue with red, white or black spots as well as thorn-like protrusions on its surface & $9(6.12)$ \\
\hline & & $\begin{array}{l}\text { a tongue less red than normal, indicating qi and blood deficiency or the presence of cold } \\
\text { deficiency }\end{array}$ & $74(50.34)$ \\
\hline & & dry tongue & $25(17)$ \\
\hline & & mirror tongue & $17(11.56)$ \\
\hline & & thin fur & $76(51.7)$ \\
\hline & & thick fur & $26(17.68)$ \\
\hline & & tongue coating white in color & $67(45.57)$ \\
\hline & & tongue coating yellow in color & $41(27.89)$ \\
\hline & & tongue coating black in color & $1(0.68)$ \\
\hline & pulse & floating pulse & $26(17.68)$ \\
\hline & & sunken pulse & $33(22.44)$ \\
\hline & & slow pulse & $15(10.2)$ \\
\hline & & rapid pulse & $13(8.84)$ \\
\hline & & strong purse & $26(17.68)$ \\
\hline & & weak purse & $28(19.04)$ \\
\hline & & string-like pulse & 27 (18.36) \\
\hline & & slippery pulse & $33(22.44)$ \\
\hline & & fine pulse & 20 (13.6) \\
\hline & & rough pulse & $2(1.36)$ \\
\hline
\end{tabular}

CRF. All clinicians and researchers involved in this study were educated on the CRF and SOPs twice yearly to remove difficulties and misunderstandings and to enhance the concordance rate. We notified all clinicians of contested issues presented in the education process to minimize individual prejudices and enhance consistency.

\section{Results}

\section{Definition of stroke in TKM and sets of subtypes}

Researchers composed the stroke identification patterns and subtypes of pattern identification from the related literature, preliminary study and expert advice. The results were then agreed upon by the Korean Medical Stroke Diagnosis Standard Committee. Based on several theories for stroke identification in the TKM literature, all possible patterns for stroke were surveyed. Stroke was defined as focal neurological-deficit symptoms from cerebral circulatory disorders, including unconsciousness, hemiplegia, sluggish speech, numbness of the skin and other symptoms. Five patterns were identified: the Fire-heat pattern, the Dampness-phlegm pattern, the Yin deficiency pattern, the Qi deficiency pattern, and the Blood stasis pattern.

\section{Fire-heat pattern}

The Fire-heat pattern is characterized by any symptom of heat or fire that is contracted externally or engendered internally. This symptom can cause stroke through intense pathogenic heat and high fever. It is generally treated by externally clearing heat or internally eliminating fire.

\section{Dampness-phlegm pattern}

The Dampness-phlegm pattern is characterized by impeding Qi movement and its turbidity, heaviness, stickiness and downward-flowing properties. This symptom is due to the accumulation of damp phlegm in the lung and spleen in TKM. This pattern is caused by stroke and circulatory disturbances.

\section{Blood stasis pattern}

The Blood stasis pattern is characterized by blood stagnation, including extravagated blood and sluggish blood circulation or viscous or congested blood, all of which may become pathogenic factors.

\section{Qi deficiency pattern}

The Qi deficiency pattern is characterized by qi deficiency with diminished internal organ function, which is marked by shortness of breath, lassitude, listlessness, spontaneous sweating, a pale tongue and a weak pulse. 


\section{Yin deficiency pattern}

The Yin deficiency pattern is characterized by yin deficiency with diminished moistening and the inability to restrain yang, which is usually manifested as fever.

\section{Draft construction by the initial adjustment of selected indicators}

Overall, pattern indicators were obtained from the above procedures (Table 3$)$. The pattern indicators were reorganized into 22 items. These items allowed TKM doctors to easily perform four examinations in stroke patients. The 22 items were: physique, headache, dizziness, complexion, eyes, tinnitus, mouth, tongue diagnosis, throat, sputum, chest, palpitation, abdomen, skin, extremities, pulse diagnosis, digestion, defecation, urine, insomnia, temperature and sweating. These items were systematically organized from the head to the foot according to the table of contents in the Dongeuibogam, the well-known encyclopedia of TKM [17]. Dongeuibogam (Treasured Paragon of Eastern Medicine) After the Japanese Invasion in year 1592, Heo, Joon received orders from King Seonjo to consolidate data with Jung,

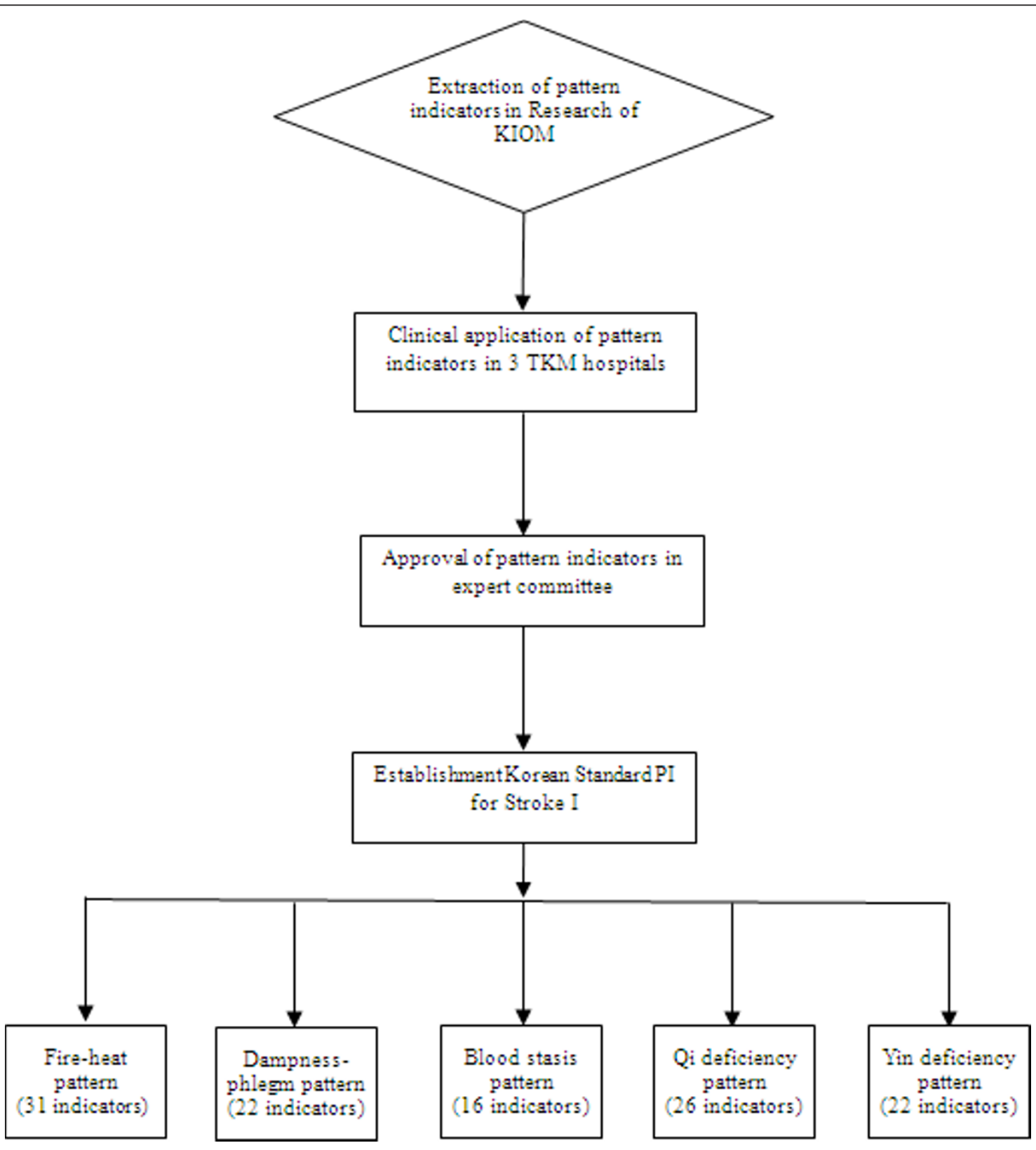

Figure 1 Flow chart of our research. 
Jak; Yang, Ye-su; Kim, Eung-tak; Lee, Myeong-won; and Jung, Ye-nam to write Dongeuibogam. Dongeuibogam is very important book in TKM several aspects. After all procedures were completed, a draft document was composed for the standardization of pattern identification for stroke (D-SPI). Overall, 122 indicators of pattern identification in stroke were obtained, excluding common symptoms, such as exercise, consciousness, and language disorders. After the selection, the indicators were integrated with the indicator for every cause and translated into Korean. When indicators had uncertain meanings, they were written in Chinese characters.

\section{Korea standard pattern identification for stroke I}

Based on the originally developed indicators, symptoms written in the foreign literature were found to have the same meaning as in the Korean literature. To determine frequency, we implemented a month-long preliminary study on 147 patients (June, 2005) in three Oriental medicine hospitals (Table 3). After this clinical field test, some pattern indicators were separated or combined, which led. Few indicators were eliminated. The remaining indicators were then discussed. The researchers developed consensus upon the Korea standard pattern identification for stroke I (K-SPI-Stroke I) to be presented at the Korean Medical Stroke Diagnosis Standard Committee on July 2005 (Figure 1), (Tables 4, 5, 6, 7 and 8).

\section{Discussion}

TKM occupies an independent position guaranteed by Korean medical laws [1]. Korea has is one national

Table 4 Indicators of the Fire-heat pattern (31)

\begin{tabular}{|c|c|}
\hline Item & pattern indicator \\
\hline \multirow[t]{6}{*}{ headache } & radiating headache(both temporal region and parietal region) \\
\hline & severe and seems to be bursting \\
\hline & hot head \\
\hline & headache with anger \\
\hline & $\underline{\text { severe and sudden headache }}$ \\
\hline & seems to break and to be bursting \\
\hline dizziness & severe and accompanied nausea and vomiting \\
\hline facial complexion & reddened complexion \\
\hline eye's abnormal condition & red eyes \\
\hline tinnitus & ringing in the ear strongly \\
\hline \multirow[t]{3}{*}{ tongue and mouth } & bitter taste and thirst in the mouth \\
\hline & aphta and tongue sores \\
\hline & fetid mouth odor \\
\hline sputum & sticky and yellow sputum \\
\hline oppression in the chest & heat vexation in the chest \\
\hline \multirow[t]{2}{*}{ palpitation and fearful throbbing } & palpitation quickly \\
\hline & palpitation with oppression \\
\hline abdomen & tenderness and fever in abdominal diagnosis \\
\hline skin & burning skin sensation \\
\hline palm and sole & vexing heat in the extremities \\
\hline \multirow[t]{2}{*}{ digestion } & feeling full and feeling gastric reflux in stomach \\
\hline & excessive appetite with increased food intake and recurrence of hunger sensation shortly after eating \\
\hline feces & hardened feces difficult to evacuate \\
\hline urine & reddish urine and does not come out easily \\
\hline sleeping & inability to sleep well due to fever and oppression \\
\hline sweating & profuse sweating with fever: sweating when having fever \\
\hline \multirow[t]{4}{*}{ tongue } & red tongue \\
\hline & a tongue with thorn-like protrusions on its surface \\
\hline & thick and yellow fur \\
\hline & dry and black fur \\
\hline purse & surging and rapid purse \\
\hline
\end{tabular}


Table 5 Indicators of the Dampness-phlegm pattern (22)

\begin{tabular}{|c|c|}
\hline Item & pattern indicator \\
\hline \multirow[t]{5}{*}{ headache } & heavy -headedness \\
\hline & $\begin{array}{l}\text { an unpleasant sensation with an urge to vomit } \\
\text { and pain in the head }\end{array}$ \\
\hline & un-refreshed head \\
\hline & tightened feeling \\
\hline & headache in whole head \\
\hline dizziness & severe and accompanied nausea and vomiting \\
\hline \multirow[t]{2}{*}{ facial complexion } & dark face discoloration \\
\hline & black face with black eyelids \\
\hline tinnitus & ringing in the ear strongly \\
\hline mouth and lip & excessive saliva in the mouth \\
\hline \multirow[t]{2}{*}{ sputum } & phlegm rale \\
\hline & sticky and yellow sputum \\
\hline $\begin{array}{l}\text { oppression in the } \\
\text { chest }\end{array}$ & feeling of oppression in the chest \\
\hline $\begin{array}{l}\text { palpitation and fearful } \\
\text { throbbing }\end{array}$ & palpitation with oppression \\
\hline abdomen & sounds heard in abdominal diagnosis \\
\hline skin & attachment sensation of derma \\
\hline digestion & an unpleasant sensation with an urge to vomit \\
\hline \multirow[t]{3}{*}{ tongue } & $\begin{array}{l}\text { larger than normal tongue, pale in color and } \\
\text { delicate, usually bearing dental indentations on } \\
\text { the margin-enlarged tongue }\end{array}$ \\
\hline & $\begin{array}{l}\text { a tongue with dental indentations on its } \\
\text { margin: a-teeth -marked tongue }\end{array}$ \\
\hline & thick and yellow or white fur \\
\hline purse & surging purse \\
\hline
\end{tabular}

TKM school and 11 traditional Korean medicine colleges offering 6-year courses. Both the national school and colleges have their own hospitals, the majority of which are filled with a considerable number of stroke patients. Thus, we chose to standardize the TKM method of stroke diagnosis. One of the decisive procedures before stroke treatment is pattern identification, which determines the therapeutic method, such as acupuncture or herbs[18]. Pattern identification in stroke is a series of collection procedures that involves not only specific neurological deficits but also unspecific symptoms and indicators obtained by four examinations as well as determining treatment goals after integrating all data. When the cause and disease conditions are determined using pattern identification, TKM doctors adopt proper therapeutic methods to restore the imbalance [19]. Specific and unspecific symptoms do not tend to be visualized or digitized but assessed comparatively and synthetically during the diagnosis process [20]. Despite this feature, a standardized diagnosis is vital for TKM. Since 1996, China has endeavored to establish standardized diagnoses to establish new criteria [12]. However,
Table 6 Indicators of the Blood stasis pattern (16)

\begin{tabular}{|c|c|}
\hline Item & pattern indicator \\
\hline \multirow[t]{3}{*}{ headache } & headache with a pulling sensation \\
\hline & site-fixed headache \\
\hline & old headache \\
\hline $\begin{array}{l}\text { facial } \\
\text { complexion }\end{array}$ & black face with black eyelid \\
\hline $\begin{array}{l}\text { eye's } \\
\text { abnormal } \\
\text { condition }\end{array}$ & purpura in the sclera \\
\hline mouth & cyanotic lips \\
\hline sputum & fishy smell mouth odor \\
\hline $\begin{array}{l}\text { oppression } \\
\text { in the } \\
\text { chest }\end{array}$ & bloated feeling in the chest and hypochondriac region \\
\hline $\begin{array}{l}\text { palpitations } \\
\text { fearful } \\
\text { throbbing }\end{array}$ & palpitation with anxiety or discomfort \\
\hline \multirow[t]{2}{*}{ abdomen } & $\begin{array}{l}\text { tension in the upper abdomen and complain of lower } \\
\text { abdominal tenderness }\end{array}$ \\
\hline & mass in the abdomen \\
\hline skin & purpura \\
\hline \multirow[t]{3}{*}{ tongue } & tongue purple in color \\
\hline & $\begin{array}{l}\text { tongue with red, white or black spots as well as thorn-like } \\
\text { protrusions on its surface }\end{array}$ \\
\hline & cyanotic tongue \\
\hline Pulse & rough pulse \\
\hline
\end{tabular}

neither developmental processes nor clinical verifications were found in the literature. This study involved verifying and standardizing clinical indicators and patterns from the classical literature. Several types of pattern identification exist, such as the cold-heat, deficiency-excess, visceral, and constitutional patterns of identification. Therefore, the first step towards standardizing pattern identification was to select only the patterns of identification most frequently observed. The diagnosis and treatment of stroke in Korea have been influenced by the publication of the Dongeuibogam, which contains medical theories of successive generations and clinical experiences from the 17th century [17]. Additionally, on halfway through the medical exchange between China and Korea, the blood stasis pattern concept was introduced. Currently, the wind, fire-heat, dampness-phlegm, blood stasis, and deficiency patterns are prevalent in clinics [4]. We constructed the patterns of Korean stroke considering pathological changes in TKM. Wind was excluded from the study because it is a pattern that explains the condition of a patient rather than the cause of stroke. Because deficiency has excessive sub-deficiency patterns, qi deficiency and yin deficiency, which were thought to be meaningful in investigating stroke, were included exclusively. The following step was to determine what clinical 
Table 7 Indicators of the Qi deficiency pattern (26)

\begin{tabular}{|c|c|}
\hline Item & pattern indicator \\
\hline \multirow[t]{3}{*}{ headache } & continuous pain \\
\hline & headache accompanied by empty pain \\
\hline & deterioration of headache by fatigue \\
\hline dizziness & slight dizziness \\
\hline facial complexion & white complexion \\
\hline tinnitus & ringing in the ear slightly \\
\hline sputum & spitting phlegm with a low viscosity \\
\hline $\begin{array}{l}\text { palpitations fearful } \\
\text { throbbing }\end{array}$ & palpitations and shortness of breath \\
\hline abdomen & no resistance to touch of the abdomen \\
\hline \multirow[t]{2}{*}{ skin } & feeling like insects' crawling \\
\hline & feeling chilly on the skin \\
\hline \multirow[t]{2}{*}{ palm and sole } & $\begin{array}{l}\text { a pronounced cold in the extremities up to the } \\
\text { knees and elbows or beyond, also the same as } \\
\text { cold extremities }\end{array}$ \\
\hline & a lack of physical strength in the four extremities \\
\hline digestion & loss of appetite \\
\hline feces & discharge of soft, unformed stools: loose stool \\
\hline \multirow[t]{2}{*}{ urine } & a high volume of transparent urine \\
\hline & failure of voluntary control of urination \\
\hline sweat & $\begin{array}{l}\text { lack of physical strength, excessive sweating } \\
\text { during the daytime with no apparent cause such } \\
\text { as physical exertion, hot weather, thick clothing or } \\
\text { medication }\end{array}$ \\
\hline voice sound & disinclined to speak at a low volume \\
\hline \multirow[t]{4}{*}{ tongue } & $\begin{array}{l}\text { larger than normal tongue, pale in color and } \\
\text { delicate, usually bearing dental indentations on } \\
\text { the margin: enlarged tongue }\end{array}$ \\
\hline & $\begin{array}{l}\text { tongue with dental indentations on its margin: a- } \\
\text { teeth-marked tongue }\end{array}$ \\
\hline & a tongue less red than normal \\
\hline & thin fur \\
\hline pulse & a pulse that is deep, soft, thin and forceless \\
\hline
\end{tabular}

indicators belonged to each identification pattern and compose a draft from the clinical data. First, primary headings were sorted from the Dongeuibogam, and clinical indicators were supplemented from the ten academic sources frequently referred to by TKM doctors. A field test confirmed the frequency and difference between significant and insignificant indicators. Then, the Korea standard pattern identification for stroke I (KSPI-Stroke I) was produced. Through the field test, we were able to investigate several indicators. Some indicators in the literature were unhelpful pattern identification for stroke (e.g., underweight or overweight), and some indicators required adjustment. For example, the tinnitus category needed to differentiate tinnitus intensity rather than tinnitus aspects. Also, some indicators of purse were combined due to their common combined use in clinical. It is notable that a consensus on clinical
Table 8 Indicators of the Yin deficiency pattern (22)

\begin{tabular}{|c|c|}
\hline Item & pattern indicator \\
\hline \multirow[t]{3}{*}{ headache } & headache accompanied by hot flush \\
\hline & continuous pain \\
\hline & $\begin{array}{l}\text { headache accompanied by empty } \\
\text { pain }\end{array}$ \\
\hline dizziness & dizziness slightly \\
\hline facial complexion & pale face and red zygomatic site \\
\hline tinnitus & ringing in the ear slightly \\
\hline \multirow[t]{2}{*}{ mouth and lip } & dry mouth \\
\hline & aphta and tongues sores \\
\hline sputum & sputum with blood \\
\hline $\begin{array}{l}\text { palpitation and fearful } \\
\text { throbbing }\end{array}$ & palpitation with anxiety or discomfort \\
\hline abdomen & $\begin{array}{l}\text { no resistance to touch of the } \\
\text { abdomen }\end{array}$ \\
\hline skin & dry skin \\
\hline palm and sole & heat in the palms and soles \\
\hline sleeping & inability to sleep due to anxiety \\
\hline heat condition & afternoon tidal fever \\
\hline sweat & night sweating \\
\hline \multirow[t]{4}{*}{ tongue } & a tongue thinner than normal \\
\hline & dry and red tongue \\
\hline & thin fur or mirror tongue \\
\hline & peeled fur \\
\hline purse & fine and rapid tongue \\
\hline
\end{tabular}

The principles for developing indicators were as follows:

1) To reflect characteristic stroke symptoms

2) To clinically identify stroke patterns based on the present state of TKM

3) To consider associations with previous studies

4) To reflect the recent trend of stroke in the TKM literature

indicator measurement was obtained. Even doctors with the same medical education can potentially conduct different assessments. Therefore, we developed the CRF and SOP to standardize and digitize clinical indicators.

A limitation of our study was that the concepts of reliability and validity, which are used to assess diagnosis criteria in modern western medicine [21], were not introduced. Additionally, the concepts of patterns and clinical indicators are rooted in the TKM literature and can generate divergences among the literature from China, Japan, and other countries in eastern Asia. Some indicators were assessed considering the feature of Korean people.

\section{Conclusions}

A strength of this study was that we determined 5 patterns and 117 clinical indicators composed of high-frequency indicators and stroke symptoms. We aimed to determine the significant clinical indicators and distinguishing patterns of stroke. Greater focus was placed on indicators of pathological conditions than on those of 
physiological conditions, and we endeavored to determine clinical significance by conducting a field test and discussions with experts. Given the high probability of different levels of experience among the experts, we first produced the CRF and SOP and placed importance on education and training to eliminate differences between experts. Consequently, we developed a systematic questionnaire after the literature search, expert consensus, and a field test, which provided an example for an objective and standardized pattern identification for stroke in TKM. We shall be able to develop various standardized differentiations of symptoms and indicators that fit the actual conditions of other disease.

\section{Acknowledgements}

This research was supported by a grant from the Korea Institute of Oriental Medicine (K11131)

\section{Author details}

${ }^{1}$ Brain Disease Research Center, Korea Institute of Oriental Medicine, 1672 Yuseongdae-ro, Yuseong-gu, Daejeon 305-811, Republic of Korea. ${ }^{2}$ National Rehabilitation Center, Seoul, South Korea.

\section{Authors' contributions}

TYP conceived the study design. TYP, TWM surveyed and reviewed all pattern indicators. JAC, BKK, MMK searched and analyzed the literature. JAL drafted the manuscript. MSL and JSL helped with the previous study and critically reviewed the manuscript. All authors read and approved the final version of the manuscript.

\section{Competing interests}

The authors declare that they have no competing interests.

Received: 31 October 2011 Accepted: 13 March 2012

Published: 13 March 2012

\section{References}

1. Kim H, Bae H, Park S, Moon S, Park J, Jung W: Clinical approach to the standardization of oriental medical diagnostic pattern identification in stroke patients. Evidence-Based Complementary and Alternative Medicine 2011, Article ID 768492, doi:10.1155/2011/768492:7

2. In A practical dictionary of Chinese medicine. second edition. Edited by: Wiseman N, Ye F. Brookline, Mass: Paradigm Publications; 1998:

3. Zhang G, Bausell B, Lao L, Handwerger B, Berman B: Assessing the consistency of traditional Chinese medical diagnosis: an integrative approach. Altern Ther Health Med 2003, 9(1):66-71, Jan/Feb 2003.

4. Kim J, Seol I, Lee I, Jo HK, Yu B, Choi S: Report on the Korean standard differentiation of the symptoms and signs for the stoke-1. Korean $J$ of Orient Physiology \& Pathology 2006, 20:229-234.

5. Go H, Kim Y, Kang B, et al: Report on the Korean standard differentiation of the symptoms and signs for the stoke-2. Korean J of Orient Physiology \& Pathology 2006, 20:1789-1791

6. Lee JA, Lee JS, Ko MM, Kang BK, Moon TW, Bang OS, Cho KH: Report on the Korean standard pattern identifications for stroke-III. Korean J Orient Int Med 2011, 32(2):232-242.

7. Huh J: Dongeuibogam Seoul: Namsandang; 2004, 336-343, 400-411, 427-431, 515-602, 654-691, 769-810, 836-861, 871-896, 1009-1011, 1196-1236, 12991344.

8. Yang K: A study of standardization of diagnoses and diagnostic requirements in traditional Korean medicine // Daejeon: Korea Institute of Oriental Medicine; 1996, 18, 32, 40, 69, 107-108.

9. Lee BK, Lim TH: In Traditional Korean Medicine Diagnostics. Volume 42.. 6 edition. Seongnam: Seongbosa; 2004:250-255.

10. Traditional Medicine Research Institute: Pattern identification Diagnostics Seoul: Seongbosa; 1995, 107-110, 116, 173-179, 190-193.
11. Association of Traditional Korean Medicine Pathology: Traditional Korean Medicine Pathology Seoul: Iljoongsa; 2002, 81-95, 205-206, 218-220, 442.

12. The collaboration group of encephalopathy emergency of state administration of traditional Chinese medicine: Guideline for diagnosis and therapeutic effect evaluation of stroke. Journal of Beijing University of TCM 1996, 19:55-56.

13. Shin SS, Shin MK, Yang KS: A study of Standardization of diagnoses and diagnostic requirements in Traditional Korean medicine III Seoul: Korea Institute of Oriental Medicine; 1997, 171-175, 180-183, 356, 450, 505. ISBN A study of Standardization of diagnoses and diagnostic requirements in Traditional Korean medicine III.

14. Moon S-J: The traditional Korean medical textbook on the digestive system Seoul: Iljoongsa; 1988, 33, 34, 43, 63, 67.

15. Association of Traditional Korean Medicine for Cardiovascular System: The traditional Korean medical textbook on the cardiovascular system Seoul: Seowondang: 1995, 74, 75, 107-113, 337.

16. Wang XZ: Traditional Chinese medicine for encephalopathy Beijing: People's medical publishing house; 2004.

17. Park CK: Study of establishment of traditional eastern Asian medicine. The Korean society of oriental medical classics 1991, 5:137-141.

18. WHO G: WHO international standard terminologies on traditional medicine in the western pacific region. Book WHO international standard terminologies on traditional medicine in the western pacific region 2007:80.

19. Zhang G, Lee W, Lao L, Bausell B, Berman B, Handwerger B: The variability of TCM pattern diagnosis and herbal prescription on rheumatoid arthritis patients. Altern Ther Health Med 2004, 10(1):58-63, Jan/Feb 2004.

20. Mantani N, Kogure T, Sakai S, Shimada Y, Tarasawa K: Reexamination of the relation between menstrual cycle and Kampo diagnosis, Yin-yang. Am J Chin Med 2003, 31(1):137-140.

21. Kim M, Cobbin D, Zaslawski C: Traditional Chinese medicine tongue inspection: An examination of the inter- and intrapractitioner reliability for specific tongue characteristics. J Altern Complement Med 2008, 14(5):527-536.

doi:10.1186/1756-0500-5-136

Cite this article as: Lee et al:: Developing indicators of pattern

identification in patients with stroke using traditional Korean medicine. BMC Research Notes 2012 5:136.

\section{Submit your next manuscript to BioMed Central and take full advantage of:}

- Convenient online submission

- Thorough peer review

- No space constraints or color figure charges

- Immediate publication on acceptance

- Inclusion in PubMed, CAS, Scopus and Google Scholar

- Research which is freely available for redistribution 